\title{
A wake-up call to educators
}

\author{
Crossing the Finish Line: Completing \\ College at America's Public Universities \\ by William G. Bowen, Matthew M. Chingos \\ and Michael S. McPherson \\ Princeton University Press: 2009. 413 pp. \\ $\$ 27.95, £ 19.95$
}

In the United States, earning a bachelor's degree is recognized as the most important factor for reducing economic inequality and increasing social mobility. But since the mid1970s, university graduation rates have stagnated and disparities in educational outcomes have risen both among ethnic minorities and among those with low socioeconomic status. In Crossing the Finish Line, authors William Bowen, Matthew Chingos and Michael McPherson analyse these troubling trends and propose solutions to help colleges support their students more effectively.

Using regression analysis, the authors tracked and compared degree-completion rates for different groups based on various criteria. They found that students with low socioeconomic status and those from ethnic minorities particularly black men and Hispanic students - were least likely to graduate. The authors also tested the predictive limitations of college admissions-test scores, the effectiveness of needbased financial aid and the ease of transferring between institutions. Although focused on the US educational system, these data contain warnings that other countries should heed.

By following the incoming class of roughly 125,000 freshmen entering their first course at 68 US universities in 1999, the authors show that degree completion has slowed to unacceptably low levels. Just $65 \%$ of full-time students graduated in four years from the most selective 'flagship' universities, and only half graduated within six years from the least selective public universities. The authors

\section{"Degree completion has slowed to unacceptably low levels."}

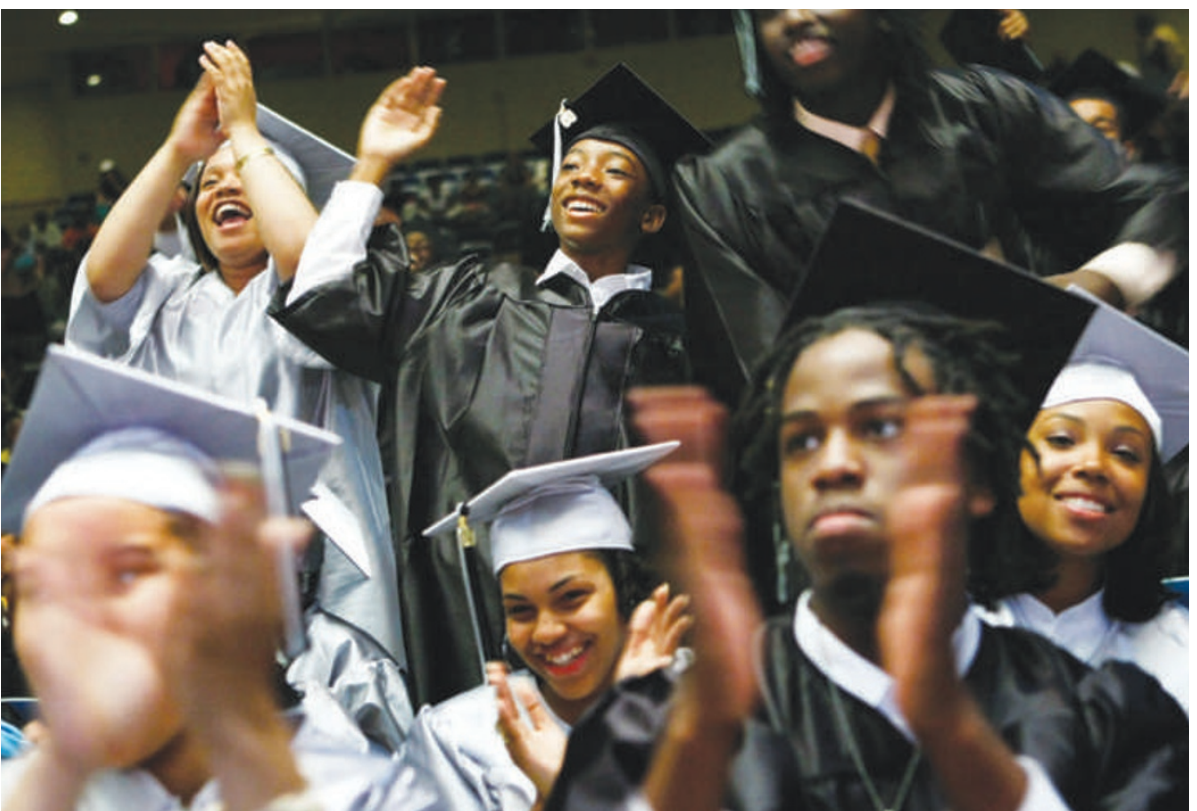

US high-school grades are a better predictor of university graduation rates than admissions-test scores.

and wealth go hand-in-hand, often conferring an advantage on white male students. Interestingly, the authors' analyses revealed that scores from the SAT and the ACT do not predict graduation rates. Instead, high-school grade-point average is the most powerful predictor of both four-year and six-year graduation rates, regardless of the quality of the high school attended. Another surprise was that the scores from tests in individual subjects were able to predict graduation rates: both Advanced Placement tests and SAT Subject Tests (additional exams required by selective universities) were strongly predictive.

The authors found that academically overqualified students who attend less-demanding schools - known as undermatching - have a significantly higher probability of never completing their argue that for those students who complete their education, delaying degree attainment from the standard four years to five or six years increases their financial burden and limits their future educational and career opportunities.

Admissions mechanisms, such as the sorting of applicants by universities and colleges and the reliance on standardized tests, dictate which types of institutions students attend. However, student scores on the SAT Reasoning Test (formerly the Scholastic Assessment Test) or the American College Test (ACT) are known to be heavily biased by gender, race and socioeconomic status, such that high test scores degrees than comparably qualified students who attend more-selective universities. This is especially prevalent among black men, they note. Many minority students and those of low socioeconomic status undermatch: $59 \%$ of students in the bottom quartile of family income do so, compared with $27 \%$ of those in the top quartile. In addition, $64 \%$ of students whose parents have no college education undermatch, compared with $41 \%$ and $31 \%$ of those whose parents have college or graduate degrees, respectively.

Difficulty in transferring between colleges also disproportionately affects students from minorities and of low socioeconomic status. For example, students who sought to save money by completing the first two years of their degree at a local community college before transferring to a more expensive public university for the remaining two years had an especially low graduation rate owing to limited transfer opportunities. However, those who did manage to gain later admission into a four-year-institution did well - better, in fact, than first-time freshmen with stronger pre-college credentials who went directly to a four-year university.

The authors' offer several solutions to these worrying trends. They include: early identification of high-performing students from disadvantaged backgrounds and then tracking them to prevent undermatching; greater investment in need-based financial aid to help qualified students of low socioeconomic status to enter a four-year institution directly; and encouraging four-year universities to accept more transfer students.

Crossing the Finish Line serves as a wake-up call to educators and administrators, and provides valuable data that will help universities to invest their resources in nurturing the talents of all their students. It also provides a disturbing glimpse of the far-reaching effects of limited expectations and diminished educational opportunities.

Devorah Bennu is a researcher and writer who writes the blog 'Living the Scientific Life (Scientist, Interrupted)' at ScienceBlogs.com. e-mail: grrlscientist@gmail.com 